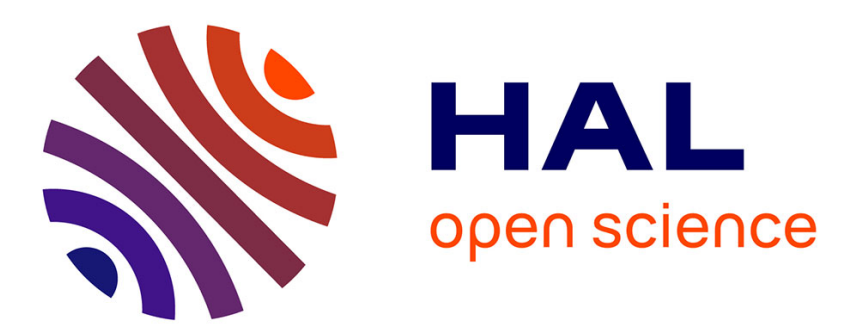

\title{
Functionalization of Carbon Nanotubes with Nickel Cyclam for the Electrochemical Reduction of CO 2
}

Silvia Pugliese, Ngoc Tran Huan, Jeremy Forte, Domenico Grammatico, Sandrine Zanna, Bao-Lian Su, Yun Li, Marc Fontecave

\section{- To cite this version:}

Silvia Pugliese, Ngoc Tran Huan, Jeremy Forte, Domenico Grammatico, Sandrine Zanna, et al.. Functionalization of Carbon Nanotubes with Nickel Cyclam for the Electrochemical Reduction of CO 2. ChemSusChem, 2020, 10.1002/cssc.202002092 . hal-03034395

\section{HAL Id: hal-03034395 \\ https: / hal.sorbonne-universite.fr/hal-03034395}

Submitted on 1 Dec 2020

HAL is a multi-disciplinary open access archive for the deposit and dissemination of scientific research documents, whether they are published or not. The documents may come from teaching and research institutions in France or abroad, or from public or private research centers.
L'archive ouverte pluridisciplinaire HAL, est destinée au dépôt et à la diffusion de documents scientifiques de niveau recherche, publiés ou non, émanant des établissements d'enseignement et de recherche français ou étrangers, des laboratoires publics ou privés. 


\title{
1 Functionalization of Carbon Nanotubes with Nickel Cyclam for the 2 Electrochemical Reduction of $\mathrm{CO}_{2}$
}

3

\author{
Silvia Pugliese, ${ }^{1,2}$ Dr. Ngoc Tran Huan, ${ }^{1}$ Jérémy Forte, ${ }^{3}$ Domenico Grammatico, ${ }^{2,4}$ Dr. Sandrine \\ Zanna ${ }^{5}$, Prof. Bao-Lian Su, ${ }^{2}$ Yun Li, ${ }^{1}$ Prof. Marc Fontecave ${ }^{1} *$
}

1. Laboratoire de Chimie des Processus Biologiques, UMR CNRS 8229, Collège de FranceCNRS-Sorbonne Université, PSL Research University,11 Place Marcelin Berthelot, 75231 Paris Cedex 05, France.

2. Laboratory of Inorganic Materials Chemistry (CMI), University of Namur, 61 rue de Bruxelles, B-5000 Namur, Belgium

3. Sorbonne Université, Institut Parisien de Chimie Moléculaire, UMR 8232 CNRS, 4 place Jussieu, 75252 Paris Cedex 5, France

4. Bio-inspired Materials Group: Functionality \& Self-assembly, Université de Pau et des Pays de l'Adour, E2S UPPA, CNRS, IPREM UMR 5254, 64000, PAU, France

5. Chimie ParisTech-PSL Research University-CNRS, Institut de Recherche de Chimie Paris (IRCP), 11 rue Pierre et Marie Curie, 75005 Paris, France

* to whom correspondence should be addressed : yun.xu-li@ college-de-france.fr; marc.fontecave@college-de-france.fr

KEYWORDS: $\mathrm{CO}_{2}$ electroreduction; nickel cyclam; pyrene; heterogenization; carbon nanotubes 
30 The exploitation of molecular catalysts for $\mathrm{CO}_{2}$ electrolysis requires their immobilization on the 31 cathode of the electrolyzer. As an illustration of this approach, a Ni-cyclam complex, with a 32 cyclam derivative functionalized with a pyrene moiety, was synthesized, shown to be a selective 33 catalyst for $\mathrm{CO}_{2}$ electroreduction to $\mathrm{CO}$ and immobilized on a carbon nanotube-coated gas diffusion 34 electrode by using a non-covalent binding strategy. The as-prepared electrode is efficient, selective, 35 robust for electrocatalytic reduction of $\mathrm{CO}_{2}$ to $\mathrm{CO}$. Very high turnover numbers (ca. 61460) and 36 turnover frequencies (ca. $4.27 \mathrm{~s}^{-1}$ ) were enabled by the novel electrode material in organic solvent37 water mixtures saturated in $\mathrm{CO}_{2}$. This material provides an interesting platform for further 38 improvement. 
Introduction

Catalysis for $\mathrm{CO}_{2}$ electroreduction into energy-dense products, such as $\mathrm{CO}$, formic acid, hydrocarbons and alcohols, has attracted extensive research attention during the last 10 years as this reaction represents one of the most promising strategies for both $\mathrm{CO}_{2}$ utilization as a carbon source and storage of intermittent renewable energy in the form of stable chemical energy. Catalysts are needed to overcome important kinetic limitations related to the multi-electron and multi-proton transfers associated with the $\mathrm{CO}_{2}$ reduction reaction $(\mathrm{CO} 2 \mathrm{RR})$. Current research focuses on both heterogeneous materials ${ }^{[1-3]}$ and homogeneous organometallic complexes. ${ }^{[4,5]}$ The former are favored industrially due to more facile product separation and catalyst regeneration and recovery. However, molecular compounds afford the opportunity to more easily design and synthetically tune the coordination environment of the active metal center. Mechanistic studies are also facilitated in that case. To reconcile these two approaches, homogeneous catalysts can be immobilized on heterogeneous conductive supports to generate cathode materials for electrolyzers. Such heterogenized molecular systems thus combine the advantages of a solid material (easy recovery of products and catalysts, efficient electron transfer from the electrode support to the catalyst, high Turnover Numbers) with those of molecular complexes (synthetic control of the electronic properties and the coordination environment of the active sites), while suppressing deactivation processes (such as dimerization) and solubility issues associated with the latter. This class of hybrid catalysts for CO2RR has been recently described in different review articles. ${ }^{[6-8]}$

Among various methods, a widely used and straightforward technique for immobilizing molecular catalysts is based on hydrophobic and $\pi-\pi$ stacking interactions between a carbon-based support, generally graphite electrodes or multi-walled carbon nanotubes (MWCNTs), and the molecular catalyst, as recently reviewed. ${ }^{[6-8]}$ MWCNTs have the advantages of stability, high electrical conductivity and high surface area. While there have been some successes regarding heterogeneous immobilization of CO2RR catalysts on carbon supports such as MWCNTs, these are few and limited mainly to polyaromatic macrocyclic ligands. ${ }^{[8]}$ For example, immobilization of a CO2RR molecular catalyst is possible without any functionalization of the ligand when the ligand is highly conjugated as in the case of metal porphyrins and phtalocyanines. ${ }^{[9-11]}$ In contrast, when the ligand, such as bipyridine or benzene-based pincer derivatives, has a limited electronic delocalized structure, an aromatic group, most often pyrene, has to be covalently added to the ligand: the pyrene group allows tight grafting of the molecular complex on carbon electrode surfaces via $\pi-\pi$ stacking interactions. Regarding such simple ligands functionalized with a pyrene group, the most 
representative reports concern bipyridine-pyrene derivatives used to immobilize a $\left[\operatorname{Re}(b p y)(\mathrm{CO})_{3} \mathrm{Cl}\right]$ complex on a graphite support ${ }^{[12]}$ or a $\left[\mathrm{Mn}(\mathrm{bpy})(\mathrm{CO})_{3} \mathrm{Br}\right]$ complex on carbon nanotubes ${ }^{[13]}$ as well as a pincer-pyrene ligand used to immobilize an Iridium complex onto a gas diffusion electrode via carbon nanotubes. ${ }^{[14]}$ The three materials displayed interesting electrochemical CO2RR catalytic properties, however in some cases with limited activity and stability.

In order to explore other classes of ligands, in particular non-aromatic in nature, and complexes based on non-noble metals, we have investigated one of the most studied molecular catalysts for $\mathrm{CO} 2 \mathrm{RR}$, namely $[\mathrm{Ni}(\text { cyclam })]^{2+}$ with cyclam $=1,4,8,11$-tetraazacyclotetradecane. To our knowledge, while the heterogenization of $[\mathrm{Ni}(\text { cyclam })]^{2+}$ complex has already been proposed, ${ }^{[15,16]}$ there is no precedent for its non-covalent immobilization on a carbon-based nanostructured electrode. For that purpose, we have synthesized an original pyrene-cyclam derivative and the corresponding Ni complex, complex 1 in Scheme 1, which was found to be a unique 6-coordinated $\mathrm{Ni}$ cyclam complex. We report here the electrocatalytic properties of complex $\mathbf{1}$ both in solution and after immobilization on MWCNTS. The complex proved to behave as a very selective homogeneous catalyst for $\mathrm{CO}_{2}$ electroreduction to $\mathrm{CO}$ in organic solvents in the presence of water. Furthermore, the presence of a pyrene moiety on the ligand was exploited to readily heterogenize the complex on MWCNTs via non-covalent interactions. The novel hybrid solid electrode, obtained by deposition of the functionalized MWCNTs on a Gas Diffusion Layer, was found to be active, stable and highly selective for $\mathrm{CO}_{2}$ electroreduction to $\mathrm{CO}$ in acetonitrile-water solvent. These results illustrate the potential of immobilized molecular catalysts for $\mathrm{CO}_{2}$ electroreduction, a class of materials yet to be developed for such an application.

\section{Results}


<smiles>Nc1ccc2ccc3cccc4ccc1c2c34</smiles>
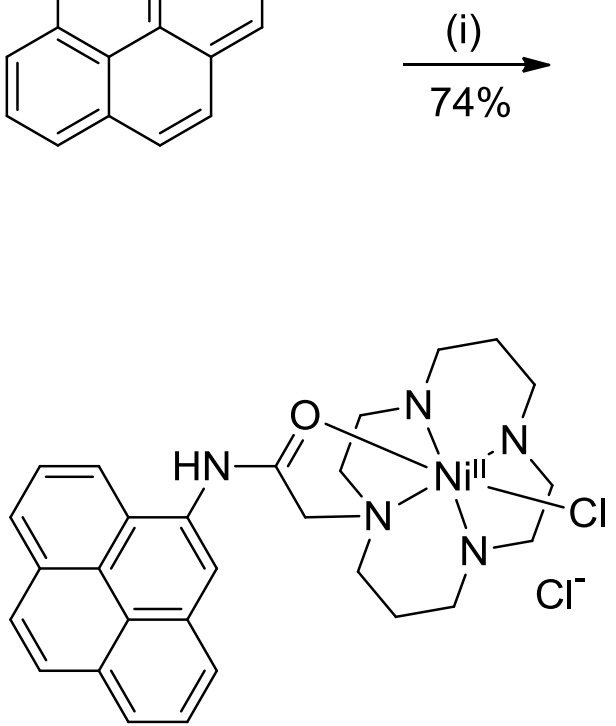

$\left[\mathrm{Ni}^{\mathrm{ll}}(\mathrm{Cl})(\mathrm{L})\right] \mathrm{Cl}(\mathbf{1})$<smiles>O=C(CCl)Nc1ccc2ccc3cccc4ccc1c2c34</smiles><smiles>C1CNCCCNCCNCCNC1</smiles>

(ii) $94 \%$

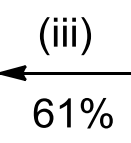<smiles>Nc1ccc2ccc3cccc4ccc1c2c34</smiles>

L

Scheme 1. Synthesis of complex 1. Conditions: (i) $\mathrm{ClCH}_{2} \mathrm{COCl}, \mathrm{NEt}_{3}, \mathrm{CH}_{2} \mathrm{Cl}_{2}$; (ii) $\mathrm{K}_{2} \mathrm{CO}_{3}, \mathrm{KI}$ (cat.), $\mathrm{CH}_{3} \mathrm{CN}$; (iii) $\mathrm{NiCl}_{2} \cdot 6 \mathrm{H}_{2} \mathrm{O}, \mathrm{EtOH}$.

In order to synthesize a $\left[\mathrm{Ni}(\text { cyclam }]^{2+}\right.$ complex bearing a pyrene group, we chose to prepare the ligand $\mathbf{L}$, in which one $\mathrm{N}$ atom of the cyclam ring is alkylated with a substituent containing a pyrene moiety (Scheme 1), according to a previously reported procedure. ${ }^{[17]}$ However, this previous synthesis gave the product in low yields and required arduous chromatographic purification. In this work, we improved the experimental procedure, especially for the $\mathrm{N}$-alkylation of the cyclam ring step, by replacing the chromatographic purification step with washing with water, and $\mathbf{L}$ could be easily synthesized on a large scale. The corresponding nickel complex $\left[\mathrm{Ni}^{\mathrm{II}}(\mathrm{Cl})(\mathrm{L})\right](\mathrm{Cl})(\mathbf{1})$ was obtained using nickel chloride hexahydrate in ethanol for metallation.

Complex 1 was isolated in the form of crystals suitable for X-ray analysis. Crystal data of all obtained structures are available in Table S1. Four different solvents, ethanol (EtOH), acetonitrile $\left(\mathrm{CH}_{3} \mathrm{CN}\right)$, dichloromethane $\left(\mathrm{CH}_{2} \mathrm{Cl}_{2}\right)$ and $\mathrm{N}$, N-dimethylformamide (DMF) were used for crystallization, resulting in different crystal packings differentially stabilized by intermolecular hydrogen bonding, $\pi$-stacking and Van der Waals interactions (Table S1). In all structures, the nickel center ion was found in a distorted octahedral coordination geometry, with a chloride ion and the oxygen atom of the amide carbonyl group occupying two ligand positions and completing the four coordinating nitrogen atoms of the cyclam ring. However, two different structures, with 
different configurations, were obtained, reflecting the presence of two isomers, named trans-1 and cis-1 in the following. Four crystal structures of trans-1 and two crystal structures of cis-1 were solved (Tables S1 and S2). In trans-1, which crystallized in all solvents used, $\mathrm{Cl}$ and $\mathrm{O}$ ligands occupy the axial positions and are thus trans to each other with respect to the Ni ion, while the four positions of the equatorial plane are occupied by the $\mathrm{N}$ atoms of the cyclam ring (Figure 1a). For the cis $\mathbf{- 1}$ isomer, which crystallized in $\mathrm{EtOH}$ and $\mathrm{DMF}, \mathrm{Cl}$ and $\mathrm{O}$ ligands are cis to each other: the equatorial plane is constituted by three $\mathrm{N}$ atoms of the cyclam ring (two secondary and one tertiary amines) and a $\mathrm{Cl}$ ligand while the apical positions are occupied by the $\mathrm{O}$ atom of the amide carbonyl group and the fourth $\mathrm{N}$ atom (one secondary amine) of the cyclam ring (Figure $1 \mathrm{~b}$ ). In the two isomers, the nickel ion, the tertiary nitrogen atom and the carbonyl oxygen atom are together part of a five-membered ring with two carbons from the dangling substituent (Figure 1). Each isomer is a racemic mixture of two enantiomers (only the R,S,S,R trans-1 and the S,S,S,S cis-1 are shown in Figure 1).

Bond lengths and angles values for all obtained crystal structures are given in Table S2. The Ni-O bond lengths are in the range of those of Ni-N (between 2.05 and $2.14 \AA$ ), while the $\mathrm{Ni}-\mathrm{Cl}$ bond lengths (between 2.40 and $2.45 \AA$ ) are slightly longer. All these values are close to those of a similar octahedral $\left[\mathrm{Ni}(\right.$ cyclam $\left.)\left(\mathrm{OH}_{2}\right)(\mathrm{Cl})\right] \mathrm{Cl}$ complex, previously reported by Zhanaidarova and al (Ni-O distance : $2.17 \AA$ and Ni-Cl distance : $2.52 \AA) .{ }^{[16]}$
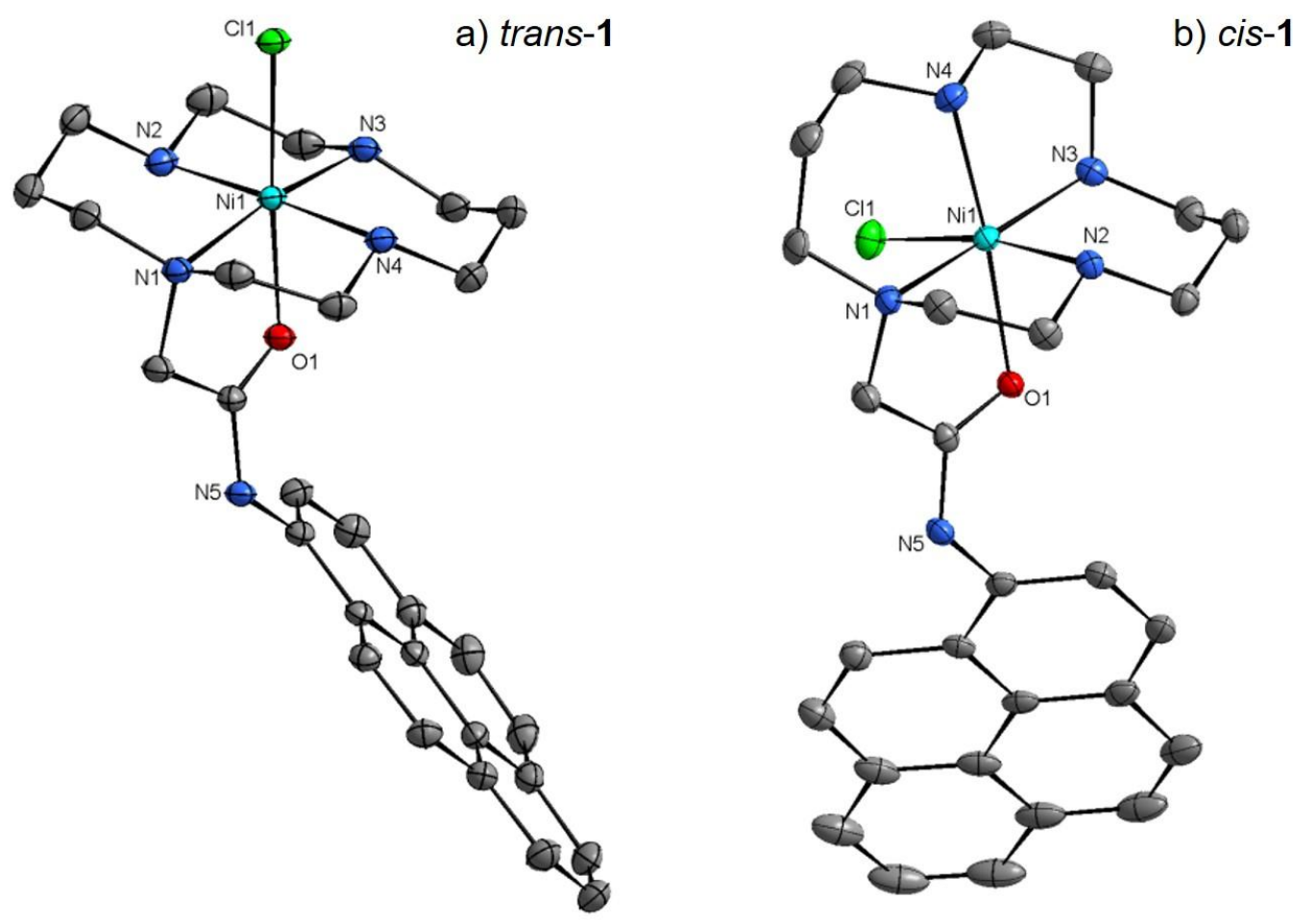
138 Figure 1. Crystal structure representation of the cation part of complex 1. Ellipsoids are drawn with $30 \%$ probability. All hydrogen atoms are omitted for the sake of clarity. (a) R,S,S,R trans-1 (from crystallization in $\mathrm{CH}_{3} \mathrm{CN}$ ); (b) $S, S, S, S$ cis-1 (from crystallization in DMF). Only one of the enantiomers is shown in both cases.

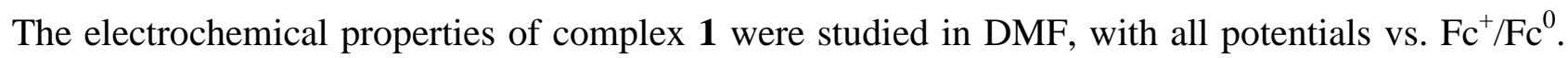
Figure 2 (dotted, dashed and black) shows the complex cyclic voltammograms (CVs) of complex 1 $(1 \mathrm{mM})$ in DMF with $0.1 \mathrm{M} \mathrm{TBAPF}_{6}$ as a supporting electrolyte on a glassy carbon disk (3 mm diameter) as a working electrode, under an argon atmosphere, when scanned down to either -2.38, 2.62 or $-3.1 \mathrm{~V}$. The complexity comes from the fact that two different complexes, trans $\mathbf{- 1}$ and cis-1, are present in solution and that the ligand itself is redox-active due to the presence of pyrene. ${ }^{[18]}$ The first feature at $-2.28 \mathrm{~V}$ was assigned to the one-electron reduction of $\mathrm{Ni}^{\mathrm{II}}$ to $\mathrm{Ni}^{\mathrm{I}}$, approximately 180 $\mathrm{mV}$ more cathodic than for the unfunctionalized $\left[\mathrm{Ni}(\text { cyclam) }]^{2+}\right.$ complex peaking at $-2.1 \mathrm{~V}$ (Figure 2, red), in agreement with a much more electron-enriched $\mathrm{Ni}$ center in complex $\mathbf{1}$ due to the presence of extra electron-donating ligands. As a confirmation of this assignment to the metal site, this feature was absent on the CV of the unmetallated pyren-cyclam ligand, $\mathbf{L}$ (Figure 2, blue). This signal is irreversible in all CVs even when reversing the scan immediately after the reduction peak, in contrast to that of $\left[\mathrm{Ni}(\text { cyclam) }]^{2+}\right.$ (Figure 2). This indicates de-coordination of $\mathrm{Cl}$ or/and $\mathrm{O}$ ligands upon reduction. Quite often, a small shoulder was present at $-2.1 \mathrm{~V}$, likely corresponding to a very small amount of the complex without $\mathrm{Cl} / \mathrm{O}$ coordination, likely in equilibrium with complex 1 in solution. A second complex irreversible feature appeared at slightly more cathodic potential (from -2.38 to $-2.65 \mathrm{~V}$ ) and proved difficult to assign. It could possibly have contributions in part from the one-electron reduction of the pyrene ring, even though the pyren-cyclam ligand, $\mathbf{L}$, exhibits a reversible signal in this potential region (Figure 2, blue). Finally, upon scanning down to below $-3.0 \mathrm{~V}$, a signal at $-2.86 \mathrm{~V}$ was observed and assigned to $\mathrm{Ni}^{\mathrm{I}}$ to $\mathrm{Ni}^{0}$ reduction. This signal is indeed absent within the $\mathrm{CV}$ of the unmetallated pyrene-cyclam ligand and is also present in the $\mathrm{CV}$ of $\left[\mathrm{Ni}(\text { cyclam) }]^{2+}\right.$ upon scanning at a potential $\left(-2.55 \mathrm{~V}\right.$ ) allowing $\mathrm{Ni}^{\mathrm{I}}$ to $\mathrm{Ni}^{0}$ conversion (Figure $\mathrm{S} 1)$. On the oxidizing return scan, the feature at $+0.2 \mathrm{~V}$, also found in the unmetallated pyrenecyclam ligand, is assigned to ligand oxidation (Figure 2). The broad signal at $-0.66 \mathrm{~V}$ was exclusively seen after scanning down to a very negative potential, and not when the cathodic scan was reversed after the second reduction wave at $-2.62 \mathrm{~V}$. This is consistent with $\mathrm{Ni}^{0}$ species generated at negative potentials and adsorbing on the surface of the electrode where they get oxidized to $\mathrm{Ni}^{\mathrm{II}}$ at $-0.66 \mathrm{~V}$ during the back scan. A similar situation was observed with the 
171 unfunctionalized $[\mathrm{Ni}(\mathrm{cyclam})]^{2+}$ complex when scanning down to very negative potentials (Figure 172 S1).

173 The cathodic peak current density $\left(j_{p}\right)$ at $-2.28 \mathrm{~V}$ varied linearly with the square root of the scan rate $174\left(v^{1 / 2}\right)$ from 0.01 to $0.5 \mathrm{Vs}^{-1}$ under Ar, consistent with diffusion-controlled processes and thus with 175 active complex 1 remaining in solution (Figure S2). We also verified that no adsorption of the 176 complex occurred at the surface of the GC electrode. Indeed, when, after 30 cycles of CV, the 177 electrode was removed from the electrolyte and used in a fresh electrolyte without complex $\mathbf{1}$, no signal corresponding to complex $\mathbf{1}$ could be observed in the $\mathrm{CV}$.

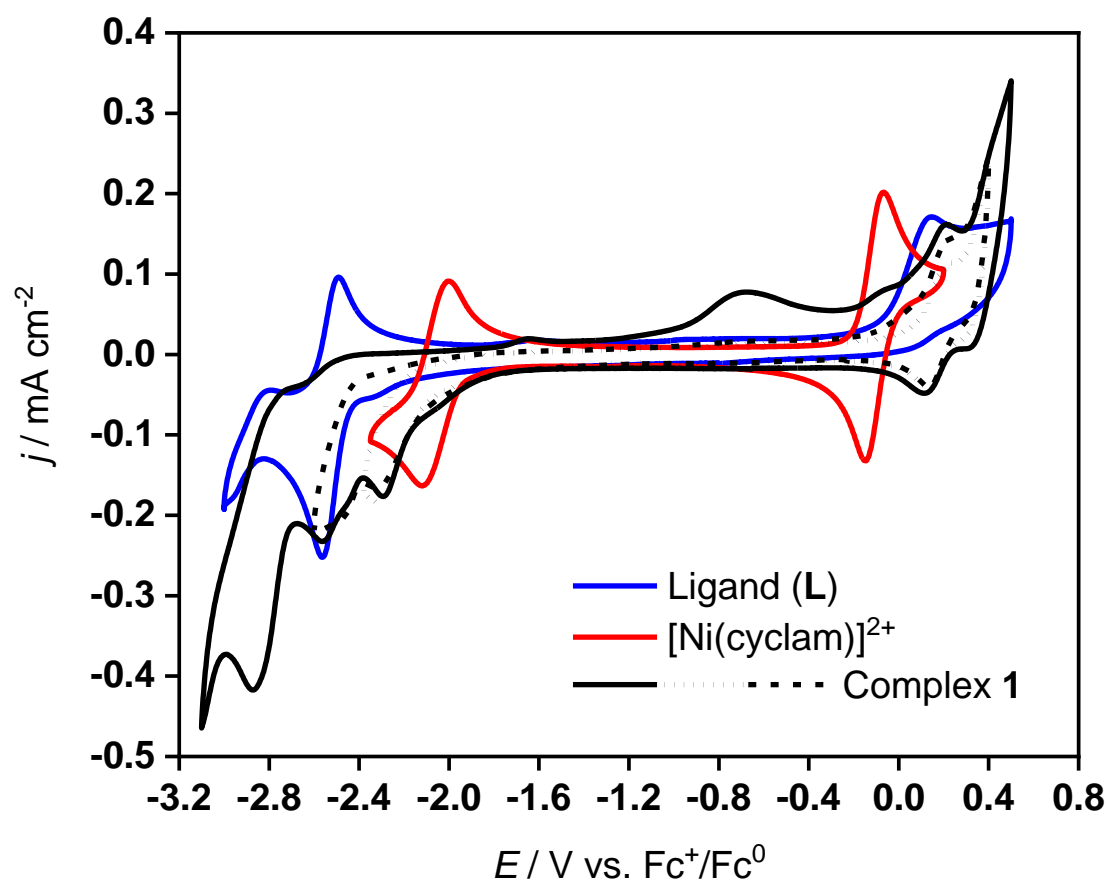

Figure 2 Cyclic voltammograms of complex 1 (black, dashed and dotted), [Ni(cyclam) $]^{2+}$ (red), ligand (L, blue). Conditions: $\mathrm{DMF}$ with $0.1 \mathrm{M} \mathrm{TBAPF}_{6}$ as the electrolyte, under Ar and at room temperature. Concentrations were $1 \mathrm{mM}$ for all species. Scan rate $100 \mathrm{mV} \mathrm{s}^{-1}$.

$\mathrm{CO}_{2}$ reduction catalyzed by complex $\mathrm{I}$

Upon addition of $\mathrm{CO}_{2}$, in the absence of a source of protons, the $\mathrm{CV}$ of $1 \mathrm{mM}$ complex 1 (Figure S3) presented a small catalytic wave with an increase of current density and a potential at half-peak catalytic current of about $-2.16 \mathrm{~V}$, more anodic that of the $\mathrm{Ni}^{\mathrm{II}} / \mathrm{Ni}^{\mathrm{I}}$ signal and with an onset 
potential close to that of $[\mathrm{Ni}(\text { cyclam })]^{2+}$. In line with previous reports on $\mathrm{CO}_{2}$ electroreduction catalyzed by $[\mathrm{Ni}(\text { cyclam })]^{2+}$, this wave is assigned to the catalytic reduction of $\mathrm{CO}_{2}$ to $\mathrm{CO}$ during which reduction of $\mathrm{Ni}^{\mathrm{II}}$ to $\mathrm{Ni}^{\mathrm{I}}$ promotes de-coordination of $\mathrm{Cl} / \mathrm{O}$ ligands and allows $\mathrm{Ni}^{\mathrm{I}}$ to bind and activate $\mathrm{CO}_{2}$ within a liberated coordination site. ${ }^{[19]}$

However, given the importance of protons in the CO2RR in general and specifically for CO2RR catalyzed by $[\mathrm{Ni}(\text { cyclam })]^{2+},{ }^{[20]}$ the effect of increased concentrations of $\mathrm{H}_{2} \mathrm{O}$ was studied by $\mathrm{CV}$ and bulk electrolysis. As expected, the catalytic current increased further upon addition of $\mathrm{H}_{2} \mathrm{O}$, from $0.4 \mathrm{M}$ to $2 \mathrm{M}$ (Figure $\mathrm{S} 4 \mathrm{a}$ ). Considering a $\mathrm{CO} / \mathrm{CO}_{2}$ reduction potential in a $\mathrm{DMF}$-water solvent mixture at $-1.41 \mathrm{~V}$ vs. $\mathrm{Fc}^{+} / \mathrm{Fc}^{0}\left(\mathrm{CO} / \mathrm{CO}_{2}\right.$ potential is reported to be $-0.690 \mathrm{~V}$ vs. $\mathrm{NHE}^{[21]}$ and the $\mathrm{Fc}^{+} / \mathrm{Fc}^{0}$ potential is reported to be $0.720 \mathrm{~V}$ vs. NHE in $\mathrm{DMF},{ }^{[22]}$ the observed onset potential at $-1.95 \mathrm{~V}$ corresponds to an overpotential of about $540 \mathrm{mV}$. In the absence of $\mathrm{CO}_{2}$, a catalytic current, assigned to proton reduction to hydrogen, also increased upon increasing the concentration of $\mathrm{H}_{2} \mathrm{O}$ (Figure $\mathrm{S} 4 \mathrm{~b}$ ), however with an onset potential more cathodic than that for $\mathrm{CO}_{2}$ reduction. This reflects the greater potential of complex 1 to catalyze the reduction of $\mathrm{CO}_{2}$. Catalysis was similarly stimulated when using 2,2,2-Trifluoroethanol (TFE) as a proton source (Figure S5). In the following, only $\mathrm{H}_{2} \mathrm{O}$ was considered as the proton source.

A controlled-potential electrolysis (CPE) was then carried out at $-2.39 \mathrm{~V}$ during which reaction products were analyzed and quantified, either by gas chromatography (for $\mathrm{CO}$ and $\mathrm{H}_{2}$ ), by Ionic Exchange Chromatography (for $\mathrm{HCOOH}$ ) and ${ }^{1} \mathrm{H}$ NMR (for $\mathrm{CH}_{3} \mathrm{OH}$ ). For that purpose, the electrochemical cell used a $1 \mathrm{~cm}^{2} \mathrm{GC}$ plate as the working electrode and the electrolyte was a solution of complex $1(1 \mathrm{mM})$ in $\mathrm{CO}_{2}$-saturated DMF containing $0.1 \mathrm{M} \mathrm{TBAPF}_{6}$ and $2 \mathrm{M} \mathrm{H}_{2} \mathrm{O}$ as a proton source. CVs obtained with such a cell reproduced nicely the above CVs (Figure S6a). After 60 minutes electrolysis (Figure S6b), CO was found as the only reaction product in the gaseous phase (faradaic yield: 96\%) and no formate could be detected in the liquid phase. The catalyst proved quite robust during 1 hour electrolysis as shown from the stability of the current density, while its activity is limited as shown by the low current density $\left(0.3 \mathrm{~mA} \cdot \mathrm{cm}^{-2}\right)$. As a further proof of the stability of the catalyst, a CV recorded after CPE was found to be comparable to that before electrolysis, except for a small decrease in intensity (Figure S6a). The same experiment but in the absence of complex 1 did not yield any $\mathrm{CO}_{2}$ reduction products.

\section{Immobilization of complex 1: preparation of the hybrid electrode and characterization}


221 Complex 1 was immobilized on MWCNTs through the establishment of $\pi-\pi$ stacking interactions 222 between the pyrene moieties and graphene motifs. In the first step, MWCNTs ( $2 \mathrm{mg})$ were first 223 sonicated in ethanol in the presence of Nafion, then drop-casted on a $1 \mathrm{~cm}^{2}$ surface of commercial 224 gas diffusion layer (GDL), consisting of a carbon fibres cloth coated with a micro-porous Teflon 225 layer embedding carbon black so as to keep electronic conductivity properties. Then the 226 MWCNT/GDL electrode was dipped into a solution of $10 \mathrm{mM}$ complex 1 in DMF, left overnight 227 and then washed with water and acetonitrile to remove any loosely bound complexes, and finally 228 air-dried before electrochemical experiments.

229 The 1/MWCNT/GDL electrode was characterized by Scanning Electronic Microscopy (SEM) and 230 X-ray photoelectron spectroscopy (XPS). As shown in Figure S7a, a porous network of MWCNTs 231 was observed in SEM images after functionalization. XPS analysis (survey spectrum) confirms the 232 presence of $\mathrm{Ni}$ and $\mathrm{N}$ atoms, from complex 1, on the surface of the electrode, together with $\mathrm{O}$ atoms 233 from alcohol or carboxylic acid defects of pristine MWCNTs (Figure S8 and Table S3). A Ni 2p $3 / 2$ 234 signal is observed at $855.9 \mathrm{eV}$ in good agreement with the presence of a $\mathrm{Ni}^{\mathrm{II}}$ ion. Since there is 235 fluoride in the deposited materials coming from Nafion with the F auger peak masking the Ni $2 p$ 236 signal at $861.47 \mathrm{eV}$, a control MWCNT/GDL electrode in the absence of complex 1 has been also 237 analysed by XPS. The peak decomposition allowed to identify the signal of Ni 2p (Figure S8 and 238 Table $\mathrm{S} 1$ ) and the ratio of $\mathrm{N} / \mathrm{Ni}$ is 4.5 approximately, whereas the $\mathrm{N}$ 1s peak was centered at 400.4 $239 \mathrm{eV}$.

240 The 1/MWCNT/GDL electrode was also characterized by Cyclic Voltammetry. CVs were recorded 241 in $\mathrm{CH}_{3} \mathrm{CN}$ containing $0.1 \mathrm{M} \mathrm{TBAPF}_{6}$, using such 1/MWCNT/GDL electrode (Figure S9). The high 242 capacitive currents observed in the voltammograms are explained by the 3D structure and the high 243 surface area of the working electrodes. Integration of the signal at $-1.7 \mathrm{~V} \mathrm{vs.} \mathrm{Fc}^{+} / \mathrm{Fc}^{0}$ 244 corresponding to $\mathrm{Ni}$ reoxidation from $\mathrm{Ni}^{\mathrm{I}}$ to $\mathrm{Ni}^{\mathrm{II}}$ allowed to determine a concentration of 245 electroactive species for the complex of $510^{-9} \mathrm{~mol} \mathrm{~cm}^{-2}$ (see experimental section). Such a value is 246 in line with previously reported values for MWCNTs functionalized with molecular Ni 247 complexes. ${ }^{[23]}$ The intensity of that peak was directly proportional to the scan rate, thus confirming 248 the immobilization of the nickel complex onto the electrode surface (Figure S9).

Immobilization of complex 1 : electroreduction of $\mathrm{CO}_{2}$.

252 The electrochemical reduction of $\mathrm{CO}_{2}$ using the new electrode material was carried out in $\mathrm{CH}_{3} \mathrm{CN}$ containing $0.1 \mathrm{M} \mathrm{TBAPF}_{6}$ as the electrolyte, in the presence of $1 \% \mathrm{H}_{2} \mathrm{O}$ as a proton source, after 
saturation with $\mathrm{CO}_{2}$. A linear sweep voltammogram (LSV) shows a catalytic wave occurring at more anodic potentials as compared to the MWCNT/GDL control electrode (Figure 3a).

Chronoamperometric measurements were carried out at various potentials from -2.34 to $-2.74 \mathrm{~V}$ vs. $\mathrm{Fc}^{+} / \mathrm{Fc}^{0}$ for $20 \mathrm{~min}$ (Figure $3 \mathrm{~b}$ ). The current density proved stable in all cases. As a matter of fact, the same electrode could be used for several independent electrolysis experiments without any loss of activity. The $\mathrm{CO}_{2}$ reduction products distribution, in terms of faradaic yields (FY), is shown in Figure 3c. CO was the major product at all potentials, with the highest FY value (92\%) obtained at $-2.54 \mathrm{~V}$ vs. $\mathrm{Fc}^{+} / \mathrm{Fc}^{0}$ (with a current density of $6 \mathrm{~mA} \cdot \mathrm{cm}^{-2}$ ). In all cases $\mathrm{H}_{2}$ accounted for less than $11 \%$ and no formate could be detected. As a control experiment, CPE using a MWCNT/GDL electrode was performed at $-2.54 \mathrm{~V}$ vs. $\mathrm{Fc}^{+} / \mathrm{Fc}^{0}$ during $20 \mathrm{~min}$ (Figure S10a). Not only the current density was much lower $\left(2.3 \mathrm{~mA} \cdot \mathrm{cm}^{-2}\right)$ but the system was selective for $\mathrm{H}_{2}$ production instead $(\mathrm{FY}=$ $83 \%$ with a FY for $\mathrm{CO}$ of $4 \%$ ). As a further control experiment, a CPE of 1/MWCNT/GDL at $2.54 \mathrm{~V}$ vs. $\mathrm{Fc}^{+} / \mathrm{Fc}^{0}$ was also run under $\mathrm{Ar}$ (Figure $\mathrm{S} 10 \mathrm{~b}$ ). Only $\mathrm{H}_{2}$ was produced after 20 min with no detectable $\mathrm{CO}_{2}$ reduction products. Finally, CPE experiments were carried out at $-2.54 \mathrm{~V}$ vs. $\mathrm{Fc}^{+} / \mathrm{Fc}^{0}$ for 20 min with increased amounts of water (3\% and 5\%). As expected, the system became much less selective for $\mathrm{CO}_{2}$ reduction, leading to $\mathrm{FY}$ for $\mathrm{CO}$ of only $22 \%$ and $12 \%$, respectively.
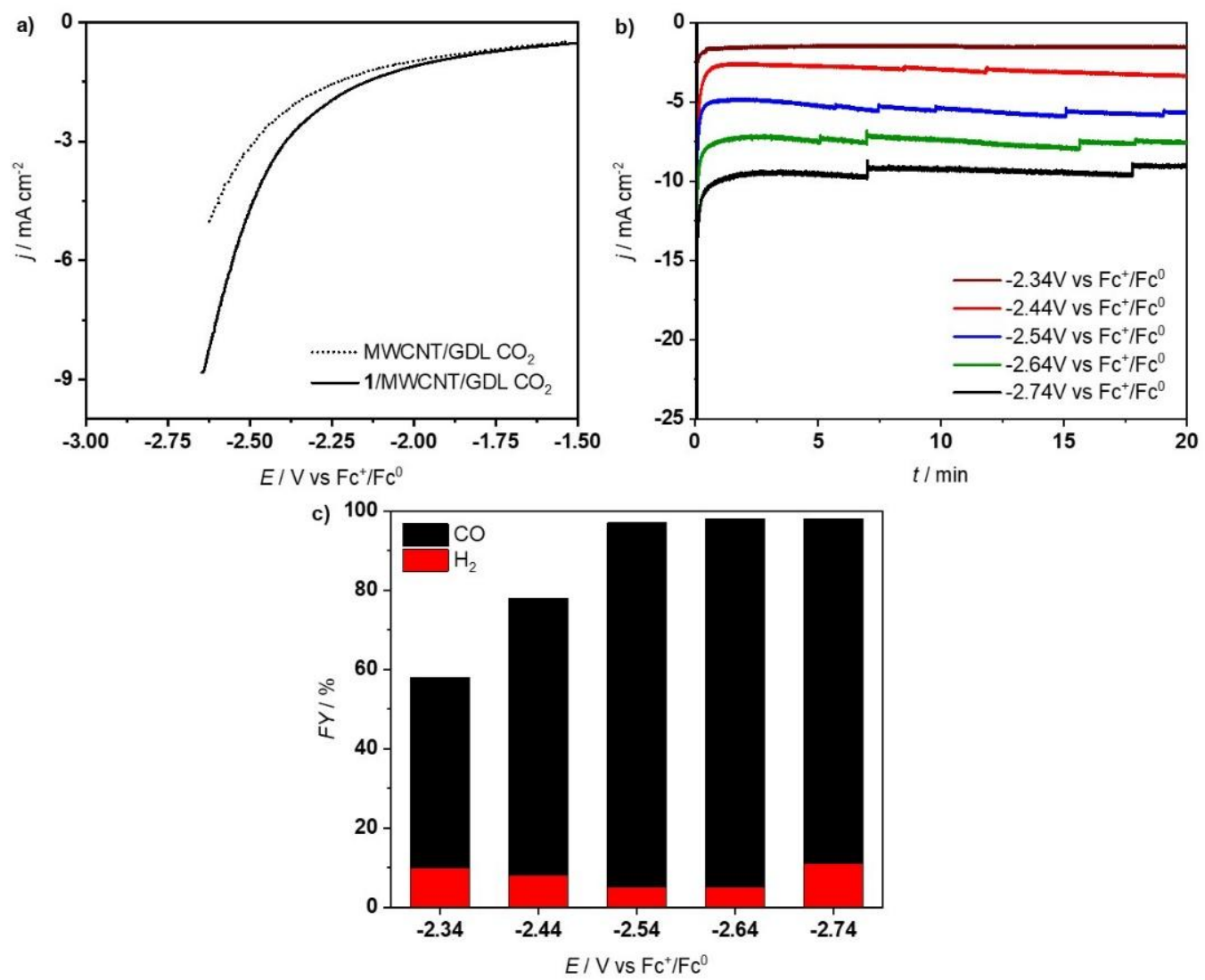
Figure 3. (a) LSV of 1/MWCNT/GDL (black) and MWCNT/GDL (dotted) in acetonitrile with TBAPF $_{6} 0.1 \mathrm{M}$ and $\mathrm{H}_{2} \mathrm{O} 1 \%$ under $\mathrm{CO}_{2}$. Scan rate $10 \mathrm{mV} \mathrm{s}^{-1}$. (b) Controlled Potential Electrolysis using 1/MWCNT/GDL as the electrode at different potentials under the same conditions. (c) Faradaic yields for $\mathrm{CO}$ and $\mathrm{H}_{2}$ after 20 min electrolysis at different potentials.

A longer experiment (4h) carried out at $-2.54 \mathrm{~V}$ vs. $\mathrm{Fc}^{+} / \mathrm{Fc}^{0}$ using the 1/MWCNT/GDL electrode under $\mathrm{CO}_{2}$ confirmed the stability of the catalytic material as well of its selectivity with a FY for CO of more than $90 \%$ after 4 h electrolysis (Figure S11). SEM (Figure S7b) as well as XPS (Figure S12) analysis after $4 \mathrm{~h}$ electrolysis showed no substantial change in the structure of the electrode. In the XPS spectrum, the Ni 2p signal was identical to that before electrolysis (Figure S12c). The decomposition of N1s also confirmed the presence of cyclam ( $\mathrm{N} 1 \mathrm{~s}$ signal at $400.3 \mathrm{eV}$ ), while an additional signal was observed at around $403 \mathrm{eV}$, typical of quarternary ammonium such as TBA present in the electrolyte. The ratio of $\mathrm{N} / \mathrm{Ni}$ was 4.05 approximately, close to the value before electrolysis.

Based on the amount of electroactive sites on the surface of the electrode $\left(510^{-9} \mathrm{~mol} \mathrm{~cm}^{-2}\right)$, a remarkable Turnover Number for CO formation of 61460 was obtained after $4 \mathrm{~h}$ electrolysis, corresponding to a Turnover Frequency value of $4.27 \mathrm{~s}^{-1}$.

\section{Discussion}

For the sake of immobilizing a $[\mathrm{Ni}(\mathrm{cyclam})]^{2+}$ complex at the surface of an electrode, a novel cyclam derivative carrying a pyrene moiety has been readily synthesized. This class of complex has been chosen not only because $[\mathrm{Ni}(\text { cyclam })]^{2+}$ is known to be a good, stable and selective molecular catalyst for $\mathrm{CO}_{2}$ electroreduction and it is based on a non-noble metal but also because, to our knowledge, there is only one precedent for carbon electrode surface modification with $[\mathrm{Ni}(\text { cyclam })]^{2+}[16]$. A $[\mathrm{Ni}(\text { cyclam })]^{2+}$ complex modified with a carboxylic acid group was used to for grafting onto titanium(zirconium) oxide surfaces but the resulting material was only studied for its properties in photoelectron transfer. ${ }^{[15]}$ The new complex $\mathbf{1}$ is a 6-coordinated Ni complex, in which the tetranuclear $\mathrm{N}$-based coordination of the cyclam ring is completed by a chloride anion and the oxygen atom of the amide group of the dangling substituent, with two different configurations, trans and cis, with respect to the relative positions of the $\mathrm{Cl}$ and $\mathrm{O}$ ligands. Coordination to a $\mathrm{Ni}^{\mathrm{II}}$ center by the oxygen atom of a pendant amide group has been recently reported in the case of substituted cyclen complexes of $\mathrm{Ni}^{[\mathrm{II}}{ }^{[24]}$ Complex $\mathbf{1}$ is thus the first $[\mathrm{Ni}(\text { cyclam })]^{2+}$ complex carrying a pyrene substituent. 
Characterization of the electrochemical properties of complex 1 in $\mathrm{DMF} / \mathrm{H}_{2} \mathrm{O}$ using a glassy carbon electrode has revealed the following features. First, upon one-electron reduction of $\mathrm{Ni}^{\mathrm{II}}$ to $\mathrm{Ni}^{\mathrm{I}}$, the complex enjoys decoordination of the $\mathrm{Cl} / \mathrm{O}$ ligand(s); this is very important since the $\mathrm{Ni}^{\mathrm{I}}$ state is the active species for $\mathrm{CO}_{2}$ binding and activation, a process that requires a free $\mathrm{Ni}$ coordination site. Second, catalysis for $\mathrm{CO}_{2}$ electroreduction occurs at the $\mathrm{Ni}^{\mathrm{II}} / \mathrm{Ni}^{\mathrm{I}}$ redox process, as shown by cyclic voltammetry, which indicates that the mechanism of the reaction catalyzed by complex $\mathbf{1}$ follows that of $[\mathrm{Ni}(\text { cyclam })]^{2+}{ }^{[25]}$ Third, as in the case of $[\mathrm{Ni}(\text { cyclam })]^{2+} \mathrm{CO}_{2}$ reduction catalyzed by complex 1 is very selective for $\mathrm{CO}$ production $(\mathrm{FY}=96 \%)$. Fourth, as expected, the activity is quite weak, providing only small current densities; indeed, $[\mathrm{Ni}(\text { cyclam })]^{2+}$ has been shown to be poorly catalytically active when using a glassy carbon electrode, while the best activities were obtained using a mercury electrode, on which the complex adsorbs and enjoys an increased reactivity both in organic and aqueous electrolytes. ${ }^{[19,20,26]}$

The pyrene-modified complex 1 has been immobilized on carbon nanotube-coated gas diffusion electrode using a non-covalent approach and the novel electrode, 1/MWCNT/GDL, has been characterized electrochemically for $\mathrm{CO}_{2}$ electroreduction. Under such an heterogenized configuration, complex 1 retained its high selectivity for $\mathrm{CO}$ production (FY above 90\%), with $\mathrm{H}_{2}$ accounting for less than $15 \%$. More interestingly, it was shown to be much more active in the immobilized form than under homogeneous conditions: current densities up to $10 \mathrm{~mA} . \mathrm{cm}^{-2}$ could be obtained as compared to $0.3 \mathrm{~mA} \cdot \mathrm{cm}^{-2}$ for a $1 \mathrm{mM}$ solution of complex 1. Finally, the derivatized electrode proved highly stable leading to impressive turnover numbers $(61460$ after $4 \mathrm{~h}$ electrolysis). This is remarkable since the electrode support is carbon-based and not mercury, so far the best electrode material for $\mathrm{CO}_{2}$ electroreduction catalysed by $[\mathrm{Ni}(\mathrm{cyclam})]^{2+}$ : this might indicate that the stable interaction between complex 1 and the carbon surface of the MWCNTs specifically favors the most reactive conformations of the complex and disfavors $\mathrm{CO}$ poisoning, $\mathrm{CO}$ desorption being the turnover-limiting step of the catalytic cycle, as does mercury for the soluble $[\mathrm{Ni}(\text { cyclam })]^{2+}$ complex. ${ }^{[20,26]}$ As a consequence, complex $\mathbf{1}$ is one of the very best molecular catalysts, after immobilization onto an electrode surface, reported so far for $\mathrm{CO}_{2}$ electroreduction, as discussed below.

The only previous attempt to graft a $[\mathrm{Ni}(\mathrm{cyclam})]^{2+}$ complex on a solid electrode (in that case a covalent grafting onto a glassy carbon electrode) was achieved by Kubiak and coworkers, using electrooxidation of a terminal alkyne attached to the cyclam ring. ${ }^{[16]}$ This led to a cathode material which proved poorly active (with current densities below $1 \mathrm{~mA} . \mathrm{cm}^{-2}$ ) and poorly selective for $\mathrm{CO}_{2}$ reduction to $\mathrm{CO}\left(\mathrm{FY}_{\mathrm{CO}}=7 \% ; \mathrm{FY}_{\mathrm{H} 2}=89 \%\right)$ under potential and solvent conditions comparable to 
those used here. The present work thus represents a great improvement regarding the utilization of solid electrodes functionalized with $[\mathrm{Ni}(\mathrm{cyclam})]^{2+}$. This is due in great part to the large surface area and the nanostructuration of the CNTs support which allow a greater density of electroactive species. As a matter of fact, the 1/MWCNT/GDL electrode is also much more efficient for $\mathrm{CO}_{2}$ reduction to $\mathrm{CO}$ than a glassy carbon electrode functionalized with a $\left[\operatorname{Re}(\mathrm{bpy})(\mathrm{CO})_{3} \mathrm{Cl}\right]$ complex using the same pyrene-dependent approach: the latter could achieve only 58 TONs during 1 hour electrolysis, after which the activity was lost. ${ }^{[12]}$ Finally, the 1/MWCNT/GDL electrode compares well with and complements the carbon nanotube-coated gas diffusion electrode derivatized with a molecular iridium pincer dihydride catalyst, which allows high TONs (200000 in 8 hours) of formate with high selectivity (> 90\%) from $\mathrm{CO}_{2}$ electroreduction in aqueous electrolytes. ${ }^{[14]}$ While based on a noble metal, the latter is a reference material with respect to carbon electrodes functionalized with a molecular catalyst for $\mathrm{CO}_{2}$ reduction. Indeed, while $\left[\mathrm{Mn}(\mathrm{bpy})(\mathrm{CO})_{3} \mathrm{Br}\right]$ was also attached to MWCNTs via $\pi-\pi$ interactions of a pyrene group, present in a bpy ligand derivative, with the CNT sidewalls, the resulting material proved much less active (low current densities), less stable, less selective (giving a mixture of $\mathrm{CO}$ and $\mathrm{HCOOH}$ together with $\mathrm{H}_{2}$ as the major product) and achieving TONs of about 1500 after $8 \mathrm{~h}$ electrolysis under aqueous conditions. $^{[13]}$

In conclusion, the present study confirms the benefits of incorporation of molecular catalysts onto electrode surfaces using the pyrene-CNT approach for $\mathrm{CO}_{2}$ electroreduction. More specifically, it shows that the $[\mathrm{Ni}(\mathrm{cyclam})]^{2+}$ complex provides an excellent platform on which further improvements of hybrid electrodes can be brought.

\section{Experimental Section}

\section{General}

All starting materials were commercially available (Sigma and TCI) and were used without further purification. Solvents were purified by an MBRAUN SPS-800 Solvent Purification System. All reactions were carried out under air atmosphere unless specified. ${ }^{1} \mathrm{H}$ and NMR spectra were recorded on a Bruker Avance-III 300 NMR spectrometer (300 MHz) at room temperature. UV-Vis spectra were recorded using a Cary 100 UV-Vis spectrophotometer instrument (Agilent).

\section{Synthesis of Complex 1}


2-Chloro- $\boldsymbol{N}$-pyren-1-yl-acetamide (2). The synthesis was carried on as previously described with slight modifications. ${ }^{[27]}$ Under an Ar atmosphere, 1-aminopyrene (5.45 g, $\left.25.1 \mathrm{mmol}\right)$ and triethylamine $(5.6 \mathrm{~mL}, 40.1 \mathrm{mmol})$ were dissolved in $\mathrm{CH}_{2} \mathrm{Cl}_{2}(500 \mathrm{~mL})$, and chloroacetyl chloride (2.8 $\mathrm{mL}, 35.1 \mathrm{mmol}$ ) was added dropwise via a syringe. After $12 \mathrm{~h}$ of stirring under Ar, the precipitate was filtered, washed with $\mathrm{H}_{2} \mathrm{O}$ and cold $\mathrm{CH}_{2} \mathrm{Cl}_{2}$ several times. The crude product was dried under vacuum over night to yield the product as a pale-grey powder which was used for the next step without further purification $(5.49 \mathrm{~g}, 74 \%) .{ }^{1} \mathrm{H} \mathrm{NMR}\left(\mathrm{CDCl}_{3}, 300 \mathrm{MHz}\right) \delta 9.01$ (br s, $\left.1 \mathrm{H}\right)$, $8.45(\mathrm{~d}, J=8.3 \mathrm{~Hz}, 1 \mathrm{H}), 8.21-8.14(\mathrm{~m}, 4 \mathrm{H}), 8.07-7.99(\mathrm{~m}, 4 \mathrm{H}), 4.42(\mathrm{~s}, 2 \mathrm{H})$. This spectrum is identical to the reported one. ${ }^{[27]}$

$N$-Pyren-1-yl-2-(1,4,8,11-tetraazacyclotetradec-1-yl)-acetamide (L). This ligand was synthesized according to a reported method with slight modifications. ${ }^{[17]}$ Under an Ar atmosphere, a mixture of cyclam (3.25 g, $16.2 \mathrm{mmol}$ ), 2-chloro- $N$-pyren-1-yl-acetamide (2) (940 mg, $3.2 \mathrm{mmol}), \mathrm{K}_{2} \mathrm{CO}_{3}$ (2.24 g, $16.2 \mathrm{mmol})$ and $\mathrm{KI}(270 \mathrm{mg}, 1.6 \mathrm{mmol})$ in $\mathrm{CH}_{3} \mathrm{CN}(677 \mathrm{~mL})$ was heated under reflux. After $24 \mathrm{~h}$, the solvent was evaporated under reduced pressure and the residue was washed with water and ether several times. The crude product was dried under vacuum overnight to yield the product as an off-white powder which was used for the next step without further purification (1.46 g, 94\%). ${ }^{1} \mathrm{H} \mathrm{NMR}\left(\mathrm{CDCl}_{3}\right) \delta 11.4$ (br s, $\left.1 \mathrm{H}\right), 8.27$ (d, $\left.J=9.3 \mathrm{~Hz}, 1 \mathrm{H}\right), 8.19-7.96(\mathrm{~m}, 8 \mathrm{H}), 3.44$ (s, 2H), $2.90(\mathrm{t}, J=5.4 \mathrm{~Hz}, 2 \mathrm{H}), 2.80(\mathrm{~m}, 8 \mathrm{H}), 2.42(\mathrm{t}, J=5.1 \mathrm{~Hz}, 2 \mathrm{H}), 2.3(\mathrm{t}, J=5.1 \mathrm{~Hz}, 2 \mathrm{H}), 2.12(\mathrm{~m}$, $2 \mathrm{H}), 1.95(\mathrm{~m}, 2 \mathrm{H}), 1.49(\mathrm{~m}, 2 \mathrm{H})$. This spectrum is identical to the reported one. ${ }^{[17]}$

Complex [Ni $\left.{ }^{\text {II }}(\mathbf{C l})(\mathbf{L})\right] \mathbf{C l}(\mathbf{1})$. A solution of $\mathbf{L}(100 \mathrm{mg}, 0.11 \mathrm{mmol})$ in EtOH $(2 \mathrm{~mL})$ was added dropwise to a solution of $\mathrm{NiCl}_{2} \cdot 6 \mathrm{H}_{2} \mathrm{O}(52 \mathrm{mg}, 0.11 \mathrm{mmol})$ in $\mathrm{EtOH}(2 \mathrm{~mL})$. The pale green solution turned immediately to orange then dark pink. After $3 \mathrm{~h}$ at room temperature, the solvent was evaporated to dryness and the blue-pink solid was dissolved in $\mathrm{EtOH}(6 \mathrm{~mL})$ and ether was allowed to slowly diffuse to this solution to give complex 1 as a pink-purple powder (78 $\mathrm{mg}, 61 \%)$. UV-Vis $[\mathrm{DMF}]: \lambda \mathrm{nm}\left(\varepsilon, \mathrm{M}^{-1} \mathrm{~cm}^{-1}\right): 543$ (10.7), 389 (1880), 353 (10920), 343 (15000), 329 (10000), 277 (16300), 266 (11060).

Single crystals suitable for X-ray diffraction were obtained by slow diffusion of $\mathrm{Et}_{2} \mathrm{O}$ into a solution of DMF containing 1 at room temperature. $\mathrm{CH}_{3} \mathrm{CN}$, EtOH and $\mathrm{CH}_{2} \mathrm{Cl}_{2}$ were also used instead of DMF giving suitable single crystals. CCDC 2021920 (trans-1, MeCN), 2021925 (trans-1, EtOH), 2021922 (trans-1, DMF), 2021923 (trans-1, DCM), 2021921 (cis-1, EtOH) and 2021924 (cis-1, DMF) contain the supplementary crystallographic data for this paper. 


\section{Homogeneous Electrochemical Studies}

All electrochemical experiments were performed on a VSP300 potentiostat (Bio-Logic Science Instruments SAS) and were conducted at room temperature in $N, N$-Dimethylformamide (DMF). 0.1 $\mathrm{M}$ tetrabutylammonium hexafluorophosphate $\left(\mathrm{TBAPF}_{6}\right)$ was used as the supporting electrolyte. The cyclic voltammetry (CV) experiments were carried out in a three electrode setup, with a $3 \mathrm{~mm}$ diameter glassy carbon (GC) electrode as a working electrode, which was polished on a polishing cloth with a $1 \mu \mathrm{m}$ diamond suspension (Struers), sonicated for 10 seconds, thoroughly rinsed with ethanol and dried prior to experiments. Platinum wire was used as a counter electrode and was previously flame annealed. The reference electrode was an $\mathrm{Ag} / \mathrm{AgCl}$ electrode in a saturated $\mathrm{KCl}$ solution, equipped with a bridge to allow operation in organic solvent. All potentials were calibrated using the ferrocene/ferrocenium $\left(\mathrm{Fc}^{+/ 0}\right)$ redox couple as an internal standard, which was added in solution at the end of each measurement. In DMF, $\mathrm{E}_{1 / 2}\left(\mathrm{Fc}^{+} / \mathrm{Fc}^{0}\right)=0.60 \mathrm{~V}$ vs $\mathrm{Ag} / \mathrm{AgCl} / \mathrm{sat}$. $\mathrm{KCl}$. Only the second cycle of all CVs are shown, although no difference in consecutive scans has been observed.

Controlled potential electrolysis (CPE) experiments were carried out in a gas-tight twocompartment electrochemical cell with two ceramic-PVDF composite membranes (16 $\mu \mathrm{m}$ thickness, Xuran) separating the anodic and cathodic compartments. The working electrode was a 1 $\mathrm{cm}^{2}$ glassy carbon plate, the counter electrode was a platinum mesh and the reference electrode was an $\mathrm{Ag} / \mathrm{AgCl}$ electrode in a saturated $\mathrm{KCl}$ solution, equipped with a bridge to allow operation in organic solvent. Anolyte and catholyte contained DMF and $2 \mathrm{M}$ of $\mathrm{H}_{2} \mathrm{O}$ as the proton source and $0.1 \mathrm{M}$ of $\mathrm{TBAPF}_{6}$ as the electrolyte. Only in the catholyte $1 \mathrm{mM}$ of complex 1 was added. Both solution compartments were saturated with $\mathrm{CO}_{2}$ during at least 20 minutes before starting the electrolysis, but no more gas was bubbled during the electrolysis. The experiments were conducted at room temperature under stirring at the cathode side. The volume of solution held by the cell in total was $22.6 \mathrm{~mL}$, with ca. $10.6 \mathrm{~mL}$ of total headspace volume.

Gas products were quantified by gas chromatography (Model 8610C SRI Instruments) equipped with TCD and FID detectors from $50 \mu \mathrm{L}$ aliquots of the headspace of the cathode compartments. Hydrogen $\left(\mathrm{H}_{2}\right)$ and carbon monoxide (CO) were detected by thermal conductivity detector (TCD) and flame ionization detector (FID), respectively. Liquid products were evaluated using an ionic exchange chromatograph (Metrohm 883 Basic IC) equipped with a Metrosep A Supp 5 column and a conductivity detector.

The faradaic yields were calculated by quantifying the products in the head-space gas of the cathodic side, on the basis of Equation 1:

$$
\text { Faradaic efficiency }=\frac{N \times F \times n}{Q} \times 100
$$


Where Q, F, and $\mathrm{N}$ represented the charge passed through the system $(\mathrm{C})$, Faraday's constant $(\mathrm{C}$ $\mathrm{mol}^{-1}$ ), and moles of $\mathrm{H}_{2} / \mathrm{CO}$ generated, respectively. In the reaction process, 2 moles of electrons were consumed to produce 1 mole of product, therefore $n=2$.

\section{Electrodes preparation and characterization}

The electrodes used a $3 \mathrm{~cm}$ x $1 \mathrm{~cm}$ gas diffusion layer (GDL, AVCarb GDS 3250, Fuel Cell Store) strip, which was briefly sonicated in EtOH and let dry in air before utilization. MWCNTs (Sigma) were used after acid treatment as following: the raw MWCNTs material were dispersed in $\mathrm{H}_{2} \mathrm{SO}_{4}(2$ $\mathrm{M}$ ), sonicated for $1 \mathrm{~h}$ at ambient temperature, washed repeatedly with $\mathrm{H}_{2} \mathrm{O}$, then EtOH and dried in a vacuum oven at $70^{\circ} \mathrm{C}$ overnight. This acid treated MWCNTs $(2 \mathrm{mg})$ were sonicated for at least 30 min in $\mathrm{EtOH}(200 \mu \mathrm{l})$ containing a solution of Nafion perfluorinated resin $(5 \mu \mathrm{l}$ of a $5 \mathrm{wt} \%$ solution in mixture of lower aliphatic alcohols containing 5\% water). The suspension was then drop-casted on the GDL $\left(1 \mathrm{~cm}^{2}\right.$ deposit $)$ and dried in air at $70^{\circ} \mathrm{C}$ for at least $30 \mathrm{~min}$. Subsequently, the GDLMWCNT electrode was immersed in a solution of complex 1 in DMF (10 mM) overnight on an orbital shaker at low speed. Finally, the electrode was dried, washed with water then acetonitrile and dried in air.

SEM images were acquired using a Hitachi S-4800 scanning electron microscope. X-ray photoelectron spectra (XPS) were collected using a Thermo Electron Escalab 250 spectrometer with a monochromated $\mathrm{Al} \mathrm{Ka}$ radiation $(1486.6 \mathrm{eV})$. The analyzer pass energy was $100 \mathrm{eV}$ for survey spectra and $20 \mathrm{eV}$ for high resolution spectra. The analysed area was $500 \mathrm{~mm}^{2}$. The photoelectron take-off angle (angle between the surface and the direction in which the photoelectrons are analysed) was $90^{\circ}$. Curve fitting of the spectra was performed with the Thermo Electron software Avantage. The electroactive sites were calculated through the integration of the oxidation wave in the CV scan (Figure S9) according to Equation 2:

$$
\Gamma N i=\frac{q}{n F A}
$$

Where $\Gamma N i$ is the number of electroactive sites $\left.(\mathrm{mol} \mathrm{cm})^{-2}\right), q$ is the charge $(\mathrm{C})$ obtained from the integration of the oxidation wave, $n$ the number of electrons in the redox process per Ni center $(n=$ $1), F$ is the Faraday constant $\left(96485 \mathrm{C} \mathrm{mol}^{-1}\right)$, and $A$ is the geometrical electrode area $\left(1 \mathrm{~cm}^{2}\right) .{ }^{[13]}$

\section{Heterogeneous Electrochemical Studies}

Linear sweep voltammetry (LSV) was performed for each sample before CPE, first under Ar and successively under $\mathrm{CO}_{2}$. Gas was bubbled in the solution for at least 20 minutes before each experiment. The scan rate was $10 \mathrm{mV} \mathrm{s}^{-1}$. CPE experiments were carried out in a gas-tight $\mathrm{H}$-shape 
cell in which cathode and reference electrode are separated from the anode by an anion exchange membrane (AMV Selemion, ACG Engineering). The solvent used was acetonitrile containing $1 \%$ of $\mathrm{H}_{2} \mathrm{O}$, and the electrolyte was $\mathrm{TBAPF}_{6}$ 0.1 M. The cathode used was a GDL on which MWCNs with the complex 1 were drop-casted as described above, the anode was platinum and the reference electrode was an $\mathrm{Ag} / \mathrm{AgCl}$ electrode in a saturated $\mathrm{KCl}$ solution, equipped with a bridge to allow operation in organic solvent. All potentials were calibrated using the ferrocene/ferrocenium $\left(\mathrm{Fc}^{+/ 0}\right)$ redox couple as an internal standard, which was added in solution at the end of each measurement. In acetonitrile, $\mathrm{E}_{1 / 2}\left(\mathrm{Fc}^{+} / \mathrm{Fc}^{0}\right)=0.54 \mathrm{~V}$ vs $\mathrm{Ag} / \mathrm{AgCl} / \mathrm{sat}$. $\mathrm{KCl} . \mathrm{CO}_{2}$ gas was bubbled in the solution for at least 20 minutes before each experiment and no more gas was bubbled during the electrolysis. The experiments were conducted at room temperature and under stirring at the cathode side. The volume of solution held by the cell in total was $22.6 \mathrm{~mL}$, with ca. $10.6 \mathrm{~mL}$ of total headspace volume.

The electrolysis products (hydrogen, $\mathrm{CO}$ and formate) were quantified in a similar manner as in the homogeneous electrochemical studies part. The faradaic yields were calculated by quantifying the products in the head-space gas of the cathodic side, on the basis of Equation 1 (see above).

The following formulas

$$
\text { TON }=\frac{\text { moles of product }}{\text { moles of catalyst }}
$$

and

$$
T O F=\frac{T O N}{\text { reaction time }[s]}
$$

were used to calculate Turnover Number (TON) and Turnover Frequency (TOF) values, respectively.

\section{Acknowledgements}

S.P. and D.G. acknowledge financial support from the European School on Artificial Leaf: Electrodes \& Devices (eSCALED). This project has received funding from the European's Union's Horizon 2020 research and innovation programme under the Marie Sklodowska-Curie grant agreement No 765376.

We thank Geoffrey Gontard (Sorbonne Universités) for solving the structure of cis-1 (DMF).

We thank Francoise Pillier (Sorbonne Universités) for the SEM images. 


\section{References}

[1] A. Liu, M. Gao, X. Ren, F. Menga, Y. Yang, L. Gao, Q. Yang, T. Ma, J. Mater. Chem. A. 2020, 8, 3541-3562.

[2] B. Kumar, J. P. Brian,V. Atla, S. Kumari, K. A. Bertram, R. T. White, J. M. Spurgeon, Catal. Today 2016, 270, 19-30.

[3] D. Gao, F. Cai, G. Wang, X. Bao, Curr. Opin. Green Sustain. Chem. 2017, 3, 39-44.

[4] R. Francke, B. Schille, M. Roemelt, Chem. Rev. 2018, 118, 4631-4701.

[5] K. Elouarzaki, V. Kannan, V. Jose, H. S. Sabharwal, J. M. Lee, Adv. Energy Mater. $2019,9$.

[6] N. Elgrishi, M. B. Chambers, X. Wang, M. Fontecave, Chem. Soc. Rev. 2017, 46, 761-796.

[7] C. Sun, R. Gobetto, C. Nervi, New J. Chem. 2016, 40, 5656-5661.

[8] L. Sun, V. Reddu, A. C. Fisher, X. Wang, Energy Environ. Sci. 2020, 13, 374-403.

[9] X. M. Hu, M. H. Rønne, S. U. Pedersen, T. Skrydstrup, K. Daasbjerg, Angew. Chemie - Int. Ed. 2017, 56, 6468-6472.

[10] Y. Wu, Z. Jiang, X. Lu, Y. Liang, H. Wang, Nature 2019, 575, 639-642.

[11] X. Zhang, Y. Wang, M. Gu, M. Wang, Z. Zhang, W. Pan, Z. Jiang, H. Zheng, M. Lucero, H. Wang, G. E. Sterbinsky, Q. Ma, Y. Wang, Z. Feng, J. Li, H. Dai, Y. Liang, Nat. Energy 2020.

[12] J. D. Blakemore, A. Gupta, J. J. Warren, B. S. Brunschwig, H. B. Gray, J. Am. Chem. Soc. 2013, 17, 30 .

[13] B. Reuillard, K. H. Ly, T. E. Rosser, M. F. Kuehnel, I. Zebger, E. Reisner, J. Am. Chem. Soc. 2017, 139, 14425-14435.

[14] P. Kang, S. Zhang, T. J. Meyer, M. Brookhart, Angew. Chemie - Int. Ed. 2014, 53, 87098713.

[15] G. Neri, J. J. Walsh, C. Wilson, A. Reynal, J. Y. C. Lim, L. Xaoe, A. J. P. White, N. J. Long, J. R. Durrant, A. J. Cowan, Phys. Chem. Chem. Phys. 2015, 17, 1562-1566.

[16] A. Zhanaidarova, C. E. Moore, M. Gembicky, C. P. Kubiak, Chem. Commun. 2018, 54, 4116-4119.

[17] N. J. Youn, J. S. Kim, K. C. Song, S. H. Kim, S. Ahn, S. K. Chang, Bull. Korean Chem. Soc. 2005, 26, 849-851.

[18] Y. Zhao, D. Xue, H. Qi, C. Zhang, RSC Adv. 2017, 7, 22882-22891.

[19] J. D. Froehlich, C. P. Kubiak, Inorg. Chem. 2012, 51, 3932-3934.

[20] J. D. Froehlich, C. P. Kubiak, J. Am. Chem. Soc. 2015, 137, 3565-3573.

[21] C. Costentin, M. Robert, J.-M. Savéant, Chem. Soc. Rev. 2013, 42, 2423-2436.

[22] S.Creager, Handbook of Electrochemistry, ed. C. Zoski Elsevier, Amsterdam, 2007, p.101.

[23] P. D. Tran, A. Le Goff, J. Heidkamp, B. Jousselme, N. Guillet, S. Palacin, H. Dau, M. Fontecave, V. Artero, Angew. Chemie - Int. Ed. 2011, 50, 1371-1374. 
534 [24] T. Qiu, G. P. A. Yap, J. Rosenthal, ACS Appl. Energy Mater. 2019, 12, 8560-8569.

535 [25] M. Beley, J. P. Collin, R. Ruppert, J. P. Sauvage, J. Am. Chem. Soc. 1986, 108, 7461-7467.

536 [26] Y. Wu, B. Rudshteyn, A. Zhanaidarova, J. D. Froehlich, W. Ding, C. P. Kubiak, V. S. $537 \quad$ Batista, ACS Catal. 2017, 7, 5282-5288.

538 [27] J. H. Kim, A. R. Hwang, S. K. Chang, Tetrahedron Lett. 2004, 45, 7557-7561.

539 